\title{
Inflammatory Reaction in Pulmonary Muscular Arteries of Patients with Mild Chronic Obstructive Pulmonary Disease
}

\author{
VICTOR IVO PEINADO, JOAN ALBERT BARBERÀ, PIETRO ABATE, JOSEP RAM íREZ, JOSEP ROCA, \\ SALUD SANTOS, and ROBERT RODRIGUEZ-ROISIN
}

Serveis de Pneumologia i Al-lèrgia Respiratòria i d'Anatomia Patològica, Institut d'Investigacions Biomèdiques Pi i Sunyer (IDIBAPS), Departament de Medicina, Hospital Clínic, Universitat de Barcelona, Barcelona, Spain

\begin{abstract}
Endothelial dysfunction and intimal thickening have been shown in pulmonary arteries (PA) of patients with mild chronic obstructive pulmonary disease (COPD). To investigate whether an inflammatory process related to tobacco smoking might be involved in the development of pulmonary vascular abnormalities in COPD, we characterized the inflammatory cell infiltrate and the endothelium-dependent relaxation in PA of 39 patients who underwent lung resection, divided into three groups: "nonsmokers" ( $n=7)$; "smokers," with normal lung function $(n=12)$; and "COPD" $(n=20)$. Endothelium-dependent relaxation was assessed in vitro by exposing PA rings to adenosine diphosphate (ADP). Inflammatory cell types were identified by immunohistochemistry. PA of COPD patients developed lower relaxation in response to ADP than nonsmokers and smokers. The number of inflammatory cells was increased in PA of COPD compared with the other two groups. This cell infiltrate was largely constituted by $\mathrm{T}$ lymphocytes. The $\mathrm{CD8}^{+} \mathrm{T}$-cell subset was increased in both smokers and COPD compared with nonsmokers, yielding a reduction of the $\mathrm{CD4}^{+} / \mathrm{CD8}^{+}$ratio. The intensity of the inflammatory infiltrate correlated with both the endothelium-dependent relaxation and the intimal thickness. We conclude that cigarette smoking induces a CD8 ${ }^{+} \mathrm{T}$-lymphocyte infiltrate in PA, which is associated with the impairment of the vessel's structure and function, suggesting the potential involvement of an inflammatory process in the pathogenesis of pulmonary vascular abnormalities in the early stage of COPD. Peinado VI, Barberà JA, Abate P, Ramírez J, Roca J, Santos S, Rodriguez-Roisin R. Inflammatory reaction in pulmonary muscular arteries of patients with mild chronic obstructive pulmonary disease.

AM J RESPIR CRIT CARE MED 1999;159:1605-1611.
\end{abstract}

Structural and functional abnormalities of the pulmonary circulation are common features in the wide spectrum of chronic obstructive pulmonary disease (COPD). Dysfunction of the pulmonary endothelium, which is associated with an impaired release of endothelium-derived nitric oxide ( $\mathrm{NO}$ ), may play a critical role in the remodeling of pulmonary vessels in COPD. Endothelial dysfunction in pulmonary arteries was initially shown in end-stage COPD patients undergoing lung transplantation by D inh-X uan and coworkers (1). In a recent study we observed that endothelial dysfunction may also be present in pulmonary arteries of patients with mild COPD (2). However, whereas in end-stage COPD chronic severe hypoxemia may account for the impairment of the endothelial function (1), the mechanisms of such an impairment in patients with milder degrees of disease, who are not hypoxemic, are unknown.

\footnotetext{
(Received in original form July 13, 1998 and in revised form November 16, 1998) Supported by Grants FIS 95/0572 and 96/0762, SEPAR-95, FUCAP-96, 1997SGR0086, and an educational grant from Zambon Spain.

Correspondence and requests for reprints should be addressed to Dr. Joan A. Barberà, Servei de Pneumologia, Hospital Clínic, Villarroel, 170. 08036 BarceIona, Spain. E-mail: jbarbera@medicina.ub.es

Am J Respir Crit Care Med Vol 159. pp 1605-1611, 1999

Internet address: www.atsjournals.org
}

Several studies performed in lungs of patients with mild COPD have shown apparent abnormalities in the structure of the pulmonary muscular arteries, in most cases consisting of the thickening of the intimal layer (3-5). Interestingly, the intensity of the intimal thickening has been shown to correlate with the severity of the inflammatory infiltrate in small airways $(5,6)$, suggesting that an inflammatory process might also account for the structural abnormalities of the pulmonary artery wall. Indeed, inflammation has been shown to be involved in the pathogenesis of some forms of pulmonary hypertension (7) and also in the remodeling of systemic vessels (8). A ccordingly, we hypothesized that the structural abnormalities and the endothelial dysfunction shown in pulmonary arteries of patients with mild COPD could be related to an inflammatory process.

Cigarette smoking causes an inflammatory reaction in the airways of patients with COPD. Whereas in both asymptomatic smokers and patients with COPD the nature and characteristics of the inflammatory reaction in central and peripheral airways (9-14), as well as in alveolar septa (15), have been thoroughly evaluated, little is known about the degree, nature, and evolution of the inflammatory infiltrate in pulmonary arteries of COPD patients.

The present study, results of which have been given in abstract form (16), was therefore addressed to investigate both 
the nature and the characteristics of the inflammatory cell infiltrate in pulmonary muscular arteries of patients with mild COPD, and to assess its relationship with both the endothelial function and the structural abnormalities of the vessel wall.

\section{METHODS}

\section{Study Population}

Thirty-nine patients (30 male/9 female) who underwent lobectomy or pneumonectomy because of lung carcinoma were studied. Pulmonary function tests (forced spirometry, lung volumes, $\mathrm{CO}$ diffusing capacity, and arterial blood gases) were performed in the days preceding surgery. No patient had clinical evidence of pulmonary hypertension. A ccording to the smoking history and the results of pulmonary function tests, patients were divided into three groups: "nonsmokers" $(n=$ 7), all of whom had normal lung function; "smokers," with lung function within the normal range $(n=12)$; and "COPD", smokers with airflow obstruction, as defined by a FEV $/$ /FV C ratio $<70 \%(n=20)$. The characteristics of the three groups of subjects are shown in Table 1.

\section{Assessment of Endothelium-dependent Vascular Relaxation}

In vitro evaluation of the endothelium-dependent relaxation of pulmonary arteries in our laboratory has been described in detail elsewhere (2). B riefly, immediately after removal, resected lung specimens were placed in cold pregassed $\mathrm{K}$ rebs-H enseleit buffer $(\mathrm{pH}=$ 7.35 to 7.45). A rterial rings with an external diameter of 1.5 to $2.5 \mathrm{~mm}$ were suspended in 10- $\mathrm{ml}$ organ bath chambers (L etica, Barcelona, Spain). Changes in isometric tension were recorded by a force transducer (Letica) connected to a polygraph. Rings were submaximally precontracted with L-phenylephrine dichloride (PE) $\left(10^{-6}\right.$ to $\left.10^{-5} \mathrm{M}\right)$ to obtain a stable plateau of tension. Endothelium-dependent vascular relaxation was tested by adding cumulative concentrations of adenosine diphosphate (A D P) $\left(10^{-10}\right.$ to $10^{-4} \mathrm{M}$ ) (Sigma Chemical Company, St. L ouis, M O) to the organ bath.

\section{Morphometric Studies}

Morphometric characteristics of pulmonary muscular arteries were analyzed in formalin-fixed, paraffin-embedded lung tissue sections processed with elastic orcein stain. A II arteries with an external diameter less than $1 \mathrm{~mm}$ and with complete elastic laminas were evaluated using a computerized image analysis system (M icrom S.A ., B arcelona, Spain) as previously described (5). E xternal and internal elastic laminas and the inner aspect of the intima were outlined, and the areas oc-

TABLE 1

GENERAL CHARACTERISTICS AND LUNG FUNCTION MEASUREMENTS*

\begin{tabular}{lccc}
\hline & Nonsmokers & Smokers & COPD \\
\hline $\mathrm{n}$ & 7 & 12 & 20 \\
Age, yr & $62 \pm 11$ & $58 \pm 10$ & $64 \pm 11$ \\
$\mathrm{FEV}_{1}, \%$ pred & $96 \pm 14$ & $99 \pm 15$ & $73 \pm 15^{\dagger \ddagger}$ \\
$\mathrm{FVC}, \%$ pred & $85 \pm 15$ & $96 \pm 15$ & $89 \pm 15$ \\
$\mathrm{FEV}_{1} / \mathrm{FVC}, \%$ & $82 \pm 6$ & $76 \pm 5$ & $59 \pm 7^{\dagger \ddagger}$ \\
$\mathrm{FEF}_{25-75 \%} \%$ pred & $126 \pm 27$ & $91 \pm 27$ & $42 \pm 15^{\dagger \ddagger}$ \\
$\mathrm{TLC}_{1} \%$ pred & $92 \pm 7$ & $100 \pm 18$ & $108 \pm 16$ \\
$\mathrm{RV}_{1} \%$ pred & $103 \pm 31$ & $113 \pm 35$ & $146 \pm 39^{\dagger \ddagger}$ \\
$\mathrm{DL}_{\mathrm{CO}}, \%$ pred & $82 \pm 14$ & $86 \pm 23$ & $90 \pm 24$ \\
$\mathrm{~Pa}_{\mathrm{O}_{2}}, \mathrm{~mm} \mathrm{Hg}$ & $96 \pm 14$ & $89 \pm 8$ & $82 \pm 10^{\dagger}$ \\
$\mathrm{Pa}_{\mathrm{CO}_{2}}, \mathrm{~mm} \mathrm{Hg}$ & $32 \pm 8$ & $36 \pm 3$ & $35 \pm 4$ \\
$\mathrm{AaPO}_{2}, \mathrm{~mm} \mathrm{Hg}$ & $14 \pm 9$ & $17 \pm 7$ & $24 \pm 8^{\dagger}$ \\
\hline
\end{tabular}

Definition of abbreviations: $\mathrm{AaPO}_{2}=$ alveolar-arterial oxygen pressure difference; $\mathrm{DL}_{\mathrm{CO}}=$ carbon monoxide diffusing capacity; $\mathrm{FEF}_{25-75 \%}=$ forced midexpiratory flow; $\mathrm{FEV}_{1}=$ forced expiratory volume in one second; $\mathrm{FVC}=$ forced vital capacity; $\mathrm{Pa}_{\mathrm{CO}_{2}}=$ partial pressure of arterial carbon dioxide; $\mathrm{Pa}_{2}=$ partial pressure of arterial oxygen; $\mathrm{RV}=$ residual volume; TLC $=$ total lung capacity

$*$ Values are mean $\pm \mathrm{SD}$.

$+p<0.05$ compared with nonsmokers.

‡ $\mathrm{p}<0.05$ compared with smokers. cupied by the muscular layer, the intimal layer, and the lumen computed, and expressed as percentage of the total area.

\section{Immunohistochemistry}

Serial sections $3 \mu \mathrm{m}$ thick were cut from formalin-fixed, paraffinembedded tissue blocks. O ne slide from each series was stained with hematoxylin-eosin (HE) for light microscopic examination and artery location purposes.

Sections were immunostained with different monoclonal antibodies using the avidin-biotin complex/horseradish peroxidase (A BC/ H R P) method (K 355; D ako, G lostrup, D enmark). B riefly, in order to inhibit peroxidase activity, sections were incubated with $0.5 \%$ hydrogen peroxide in methanol. A fter three washouts with phosphate-buffered saline (PBS), nonspecific binding was suppressed by incubation with normal goat serum. Then, one of the following primary monoclonal antibodies was used optimally diluted: anti-human leukocyte common antigen (M 701), anti-CD 45R ${ }^{+}$(U CH L 1) (M 742) for activated T lymphocytes, anti-CD 20 (M 755) for B lymphocytes, and antiCD 68 (M 0814) for macrophages/monocytes (all from D ako). N eutrophils were assessed using a mouse monoclonal primary antibody that recognizes the human neutrophil elastase (M 752; D ako). A fter three washouts in PBS, sections were incubated with biotinylated rabbit anti-mouse immunoglobulin (E 0354; Dako) followed by treatment with the A B C/H R P. I mmunopositive cells were visualized by immersing sections in a solution of diaminobenzidine (DA B) and hydrogen peroxide.

In a second set of experiments, we characterized the T-lymphocyte subpopulations on the same blocks using the following primary monoclonal antibodies optimally diluted: anti-CD 3 (NCL-CD 3-PS1) for T lymphocytes, anti-CD 4 (NCL-CD 4-1F6) for helper T lymphocytes, and anti-CD 8 (NCL -CD 8-4B 11) for cytotoxic T Iymphocytes (all from Novocastra, N ewcastle, UK).

Sections from human tonsil were used as positive controls, whereas slides without primary antibody were used as negative controls.

A rteries cut in transverse section were selected for examination from the HE stain in each subject. A t a magnification $100 \times$ the adventitial surface was measured as the area comprised between the external elastic lamina and the external edge of the dense connective tissue surrounding the artery, onto a digitizing tablet of a computer.

In each artery, positive cells in the adventitia for each monoclonal stain were counted and reported as cells per square millimeter of adventitia. The final result was a single value per patient obtained from the average of all the measurements performed in each individual and monoclonal antibody. To analyze the potential bronchiolar origin of inflammatory cells infiltrating the adventitia of pulmonary arteries, we subsequently counted separately the number of cells in arteries adjacent ( $5 \pm 1$ arteries per patient) and distant ( $4 \pm 1$ arteries per patient) to bronchioles. In order to assess the repeatability of cell counting, three sections randomly selected (10 arteries each) were re-

TABLE 2

\section{VASCULAR REACTIVITY AND MORPHOMETRIC CHARACTERISTICS OF PULMONARY ARTERIES*}

\begin{tabular}{lcccc}
\hline & Nonsmokers & Smokers & COPD & p Value \\
\hline Contraction to PE, mg & $997 \pm 275$ & $958 \pm 209$ & $992 \pm 302$ & 0.935 \\
Maximal relaxation to ADP, \% & $81 \pm 14$ & $75 \pm 13$ & $59 \pm 23^{\dagger+}$ & 0.019 \\
$\mathrm{EC}_{50}$ to ADP, $-\log [\mathrm{M}]$ & $7.1 \pm 0.6$ & $6.9 \pm 0.4$ & $6.9 \pm 0.5$ & 0.788 \\
Measured external diameter, $\mu \mathrm{m}$ & $136 \pm 70$ & $133 \pm 47$ & $112 \pm 23$ & 0.269 \\
Perimeter, $\mu \mathrm{m}$ & $759 \pm 435$ & $732 \pm 228$ & $623 \pm 116$ & 0.288 \\
Total area, $\mathrm{mm}^{2} \cdot 10^{-4}$ & $291 \pm 299$ & $244 \pm 151$ & $185 \pm 96$ & 0.298 \\
Lumen area, \% total area & $43 \pm 8$ & $37 \pm 9$ & $36 \pm 8$ & 0.113 \\
Intimal area, \% total area & $21 \pm 5$ & $27 \pm 6^{\dagger}$ & $29 \pm 6^{\dagger}$ & 0.013 \\
Muscular area, \% total area & $36 \pm 5$ & $36 \pm 7$ & $36 \pm 6$ & 0.971
\end{tabular}

Definition of abbreviations: $\mathrm{ADP}=$ adenosine diphosphate; $\mathrm{EC}_{50}=$ concentration needed to reach $50 \%$ of maximal relaxation; $\mathrm{PE}=\mathrm{L}$-phenylephrine.

$*$ Values are mean \pm SD.

${ }^{\dagger} \mathrm{p}<0.05$ compared with nonsmokers.

${ }_{f} \mathrm{p}<0.05$ compared with smokers. 
TABLE 3

INFLAMMATORY CELL COUNTS IN THE ADVENTITIA OF PULMONARY MUSCULAR ARTERIES*

\begin{tabular}{|c|c|c|c|c|}
\hline & Nonsmokers & Smokers & COPD & p Value \\
\hline Arteries/patient & $9 \pm 2$ & $9 \pm 2$ & $10 \pm 2$ & 0.575 \\
\hline Adventitial surface, $\mathrm{mm}^{2} \cdot 10^{-4}$ & $280 \pm 80$ & $370 \pm 130$ & $320 \pm 120$ & 0.213 \\
\hline \multicolumn{5}{|l|}{ Cell counts } \\
\hline Total leukocytes & $262 \pm 164$ & $363 \pm 180$ & $536 \pm 206^{\ddagger \S}$ & 0.004 \\
\hline T lymphocytes & $226 \pm 71$ & $306 \pm 142$ & $439 \pm 223^{\ddagger}$ & 0.021 \\
\hline Activated T Iymphocytes & $194 \pm 75$ & $303 \pm 148$ & $449 \pm 169^{\ddagger \S}$ & 0.001 \\
\hline \multicolumn{5}{|l|}{ T-cell subsets } \\
\hline $\mathrm{CD}^{+}$ & $231 \pm 70$ & $201 \pm 155$ & $296 \pm 147$ & 0.172 \\
\hline $\mathrm{CD}^{+}$ & $106 \pm 48$ & $230 \pm 117^{\ddagger}$ & $299 \pm 157^{\ddagger}$ & 0.008 \\
\hline $\mathrm{CD}^{+} / \mathrm{CD}^{+}$ratio & $1.9 \pm 1.0$ & $0.9 \pm 0.5^{\ddagger}$ & $1.1 \pm 0.5^{\ddagger}$ & 0.005 \\
\hline B lymphocytes & $0.0 \pm 0.0$ & $0.3 \pm 0.9$ & $0.5 \pm 1.3$ & 0.602 \\
\hline Macrophages & $0.9 \pm 2.3$ & $6.2 \pm 15.5$ & $2.1 \pm 6.7$ & 0.433 \\
\hline Neutrophils & $11.7 \pm 17.0$ & $6.0 \pm 7.5$ & $3.3 \pm 6.1$ & 0.124 \\
\hline
\end{tabular}

$*$ Values are mean $\pm \mathrm{SD}$

${ }^{\dagger}$ Number of labeled cells per $\mathrm{mm}^{2}$ of adventitia.

${ }^{\ddagger} \mathrm{p}<0.05$ compared with nonsmokers.

$\S \mathrm{p}<0.05$ compared with smokers.

counted by the same observer and intraobserver variation was calculated.

\section{Statistics}

A II data are expressed throughout as mean \pm SD. Measurements from the three groups were compared by using one-way analysis of variance (A NOVA), after assessing both normality of distributions and homoscedasticity. When the $F$ value indicated significant differences among group means, post hoc pairwise multiple comparisons were performed using the Student-N ewman-K euls test, set at an overall $\alpha$-level of 0.05 . R elationships between variables were assessed using the Pearson's correlation test.

\section{RESULTS}

Patients in the COPD group showed moderate airflow obstruction ( $\mathrm{FEV}_{1}, 73 \pm 15 \%$ of predicted; $\mathrm{FEV}_{1} / \mathrm{FVC}, 59 \pm$ $7 \%$ ) and mild gas exchange disturbances, as shown by an increased $\mathrm{AaPO}_{2}(24 \pm 8 \mathrm{~mm} \mathrm{H} \mathrm{g})$. $\mathrm{Y}$ et, $\mathrm{Pa}_{\mathrm{O}_{2}}$ was greater than 80 $\mathrm{mm} \mathrm{Hg}$ in the majority of cases (Table 1 ). Compared with both nonsmokers and smokers, there was an impaired endothelium-dependent vascular relaxation in pulmonary artery rings from COPD patients, as shown by a reduction in the maximal relaxation induced by ADP (Table 2 ). Compared with nonsmokers, the intimal layer of pulmonary muscular ar-

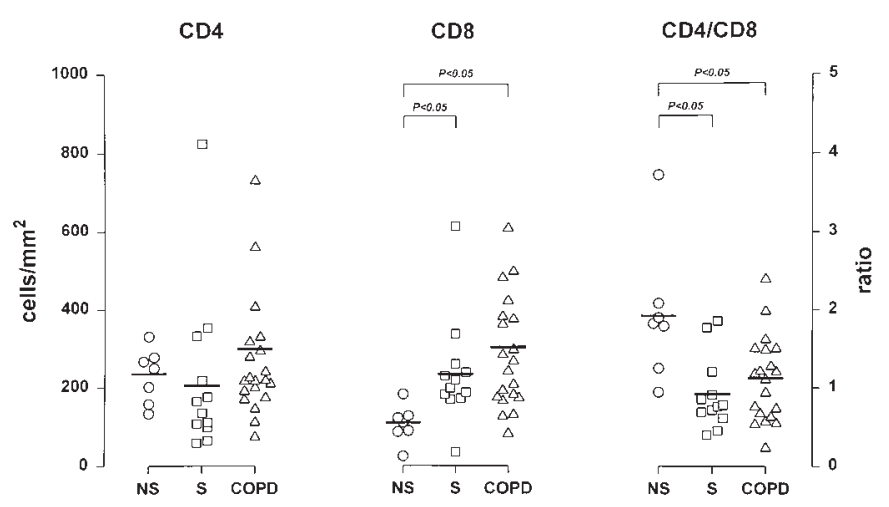

Figure 1. Counts of $\mathrm{CD}^{+}$and $\mathrm{CD}^{+} \mathrm{T}$ lymphocytes, and the $\mathrm{CD}^{+} / \mathrm{CD}^{+}$ratio in nonsmokers (NS), smokers with normal lung function (S), and patients with COPD. teries was thickened to a similar degree in both COPD patients and smokers (Table 2).

Table 3 summarizes the results of the inflammatory cell counts in the three groups of patients. COPD patients showed an increased number of leukocytes infiltrating the arterial adventitia, as compared with both nonsmokers and smokers. This increased leukocytic infiltrate was mainly constituted by activated T lymphocytes, as shown by an increased number of CD 3 and CD 45R $O$ positive cells in the arterial adventitia. No significant differences among the three groups were observed in the number of B lymphocytes, macrophages, and neutrophils. Immunostaining with CD 4 and CD 8 monoclonal antibodies indicated that the $C D 8^{+} \mathrm{T}$-cell subset was increased in both COPD patients and smokers, as compared with nonsmokers (Table 3, Figures 1 and 2), whereas no differences in the number of $\mathrm{CD} 4^{+} \mathrm{T}$ cells were shown among the three groups. A ccordingly, the ratio $\mathrm{CD} 4^{+} / \mathrm{CD} 8^{+}$was significantly reduced in both COPD patients and smokers, as compared with nonsmokers (Table 3, Figure 1).

To analyze if cells infiltrating the arterial adventitia could have originated from the bronchioles adjacent to the arteries, we identified pulmonary muscular arteries not adjacent to bronchioles in each section, and the number of cells in arteries distant and close to bronchioles were counted separately. Interestingly, in COPD patients the greater increase of leukocytes was observed in the muscular arteries distant from the airways ( $698 \pm 317$ versus $392 \pm 203$ cells $/ \mathrm{mm}^{2}$, in arteries distant and close to bronchioles, respectively; $p<0.05$ ) (Figure 2 ). No differences in cell counts were shown in arteries of both smokers and nonsmokers in relation to their proximity of bronchioles. Furthermore, in arteries close to the bronchioles we computed separately the number of cells located in the wall segment adjacent to the bronchiole as well as in the opposite wall segment. E ven though in these arteries the density of leukocytes was greater in the area adjacent to the bronchiole ( $556 \pm 364$ cells $/ \mathrm{mm}^{2}$ in the CO PD group) than in the opposite area (389 \pm 246 cells $\left./ \mathrm{mm}^{2}\right)$, the difference was not statistically significant ( $p=0.08$ ) (Figure $2 A$ ).

The total numbers of leukocytes and activated T Iymphocytes (CD 45R O ${ }^{+}$cells) found in the adventitia of pulmonary muscular arteries were inversely related to the $F E V_{1} / F V C$ ratio $(r=-0.45$ and $r=-0.46$, respectively; $p<0.01$ each) ( $F$ igure $3 A$ ). Similarly, the number of leukocytes and that of CD 45R $\mathrm{O}^{+}$cells in the muscular arteries were also inversely related to the endothelium-dependent vascular relaxation of 

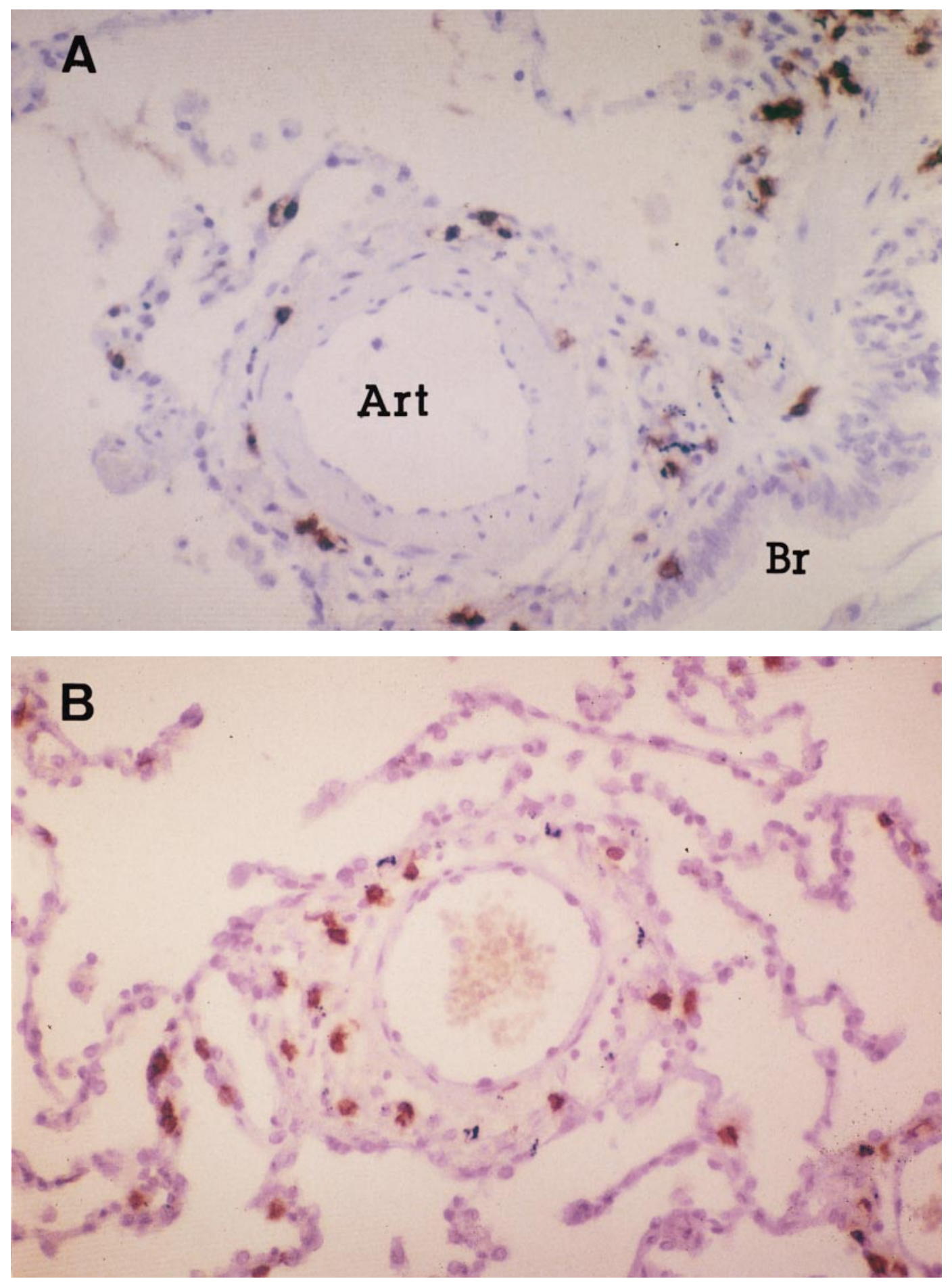

Figure 2. Photomicrographs of pulmonary muscular arteries from patients with COPD immunostained with monoclonal antibody against CD8. Positive cells (brown) were located in the adventitia of both arteries close to bronchioles ( panel A) and arteries distant from bronchioles ( panel B). (Br = bronchiolar lumen; Art $=$ arterial lumen). Original magnification: $\times 200$.

small conducting arteries, as indicated by the maximal relaxation induced by A D P ( $r=-0.38$ and $r=-0.35$, respectively; $p<0.05$ each) (Figure 3B). Furthermore, a significant relationship was also shown between the severity of the inflammatory infiltrate and the thickness of the intimal layer in the pulmonary muscular arteries ( $r=0.45$ and $r=0.44$; number of leukocytes and CD 45R $\mathrm{O}^{+}$cells, respectively; $\mathrm{p}<0.01$ each)
(Figure $3 C$ ). The intraobserver coefficient of variation in cell counts was $8.4 \%$.

\section{DISCUSSION}

The present study shows an increased number of inflammatory cells in the adventitia of pulmonary muscular arteries in 
A

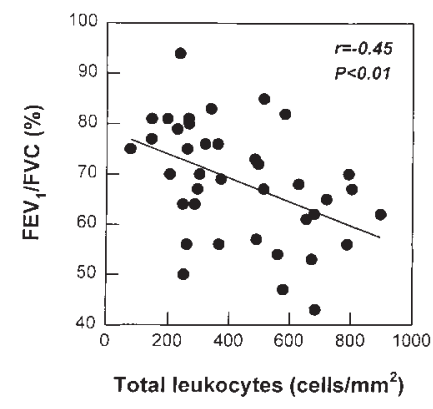

B

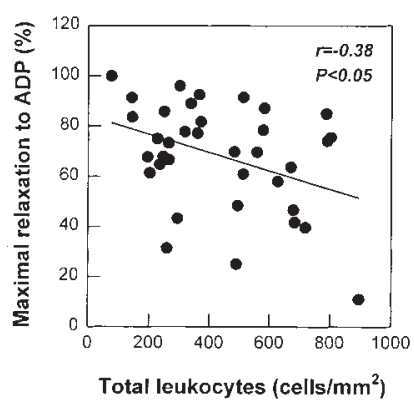

C

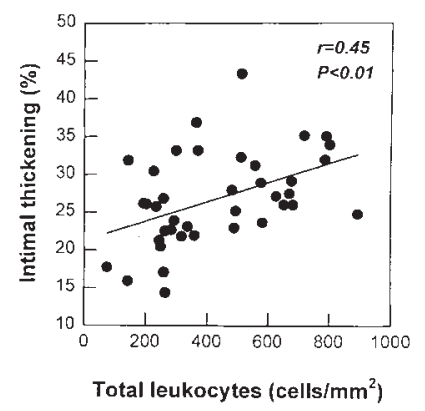

Figure 3. Relationships between the number of leukocytes infiltrating the adventitia of pulmonary muscular arteries and the degree of airflow obstruction (A), the endothelium-dependent vascular relaxation of small conducting arteries (B), and the thickness of the intimal layer of pulmonary muscular arteries (C).

patients with mild COPD, when compared with nonsmokers and smokers without airflow obstruction. This inflammatory reaction was largely constituted by activated T lymphocytes, with a predominance of the $\mathrm{CD} 8^{+} \mathrm{T}$-cell subset. The intensity of the inflammatory infiltrate in the arteries was associated with both an impaired endothelium-dependent vascular relaxation and the thickening of the intimal layer.

The presence of inflammatory infiltrate in pulmonary arteries of patients with COPD suggests that an inflammatory process might be involved in the pathogenesis of the structural and functional alterations of the vascular bed in patients with COPD. Classically, hypoxia has been considered the major pathogenetic factor of the vascular abnormalities in COPD and other chronic respiratory disorders (17). However, the demonstration of significant structural abnormalities in pulmonary muscular arteries of asymptomatic smokers (6) and patients with mild COPD undergoing resective lung surgery (3-5) questioned hypoxemia as the exclusive mechanism for the pulmonary vascular abnormalities, since $\mathrm{Pa}_{\mathrm{O}_{2}}$ was normal or only mildly impaired in most of the patients. Further, in a previous study we have also shown an impairment of the endothelium-dependent vascular relaxation in pulmonary arteries of patients with mild COPD who were not severely hypoxemic (2). The present finding of leukocytic infiltrate in arteries of patients with mild COPD supports the hypothesis that in the early stages of COPD alterations of the pulmonary circulation might have an inflammatory origin.

It is well established that chronic inflammation in peripheral airways plays a primary role in the evolution of the structural derangement that takes place in COPD (18). The evidence for this derives from studies demonstrating an increased number of inflammatory cells $(10,14,19)$, their activation status (20), and the release of putative proinflammatory mediators (21). In our study we have demonstrated an increased number of leukocytes infiltrating the adventitia of pulmonary muscular arteries in CO PD patients, largely constituted by activated $T$ lymphocytes. This finding is consistent with recent studies showing that patients with COPD have an increased number of $\mathrm{T}$ lymphocytes in both large $(9,11,13)$ and peripheral airways $(10,14)$, as well as in alveolar septa (15). Therefore, $T$ lymphocytes seem to play an important role in the onset and maintenance of a chronic inflammatory response in the different lung structures in patients with CO PD. A ccording to this notion, it is interesting to point out that in our series the intensity of the inflammatory infiltrate correlated with the degree of airflow obstruction (Figure $3 \mathrm{~A}$ ), suggesting that as the disease progresses the inflammatory reaction in pulmonary arteries may become more severe. This finding is in agreement with a recent report by Saetta and coworkers (14) showing an inverse relationship between the number of $C D 8^{+} T$ lymphocytes in peripheral airways and $F E V_{1}$, and suggests the potential involvement of these cells in the pathogenesis of COPD.

In our series, the number of $C D 8^{+} T$ lymphocytes was significantly greater in both COPD patients and smokers, compared with nonsmokers. By contrast, the number of CD $4^{+} \mathrm{T}$ cells did not differ among groups. A gain, this observation is in keeping with recent studies reporting an increased proportion of the CD $8^{+} \mathrm{T}$-cell subset in bronchial biopsy specimens $(9$, 13), and in bronchial glands (22) and peripheral airways (14) of surgically resected lung specimens of smokers with symptoms of chronic bronchitis and patients with COPD. Interestingly, a decrease of the $C D 4^{+} / C D 8^{+}$ratio in smokers with and without airflow obstruction has been shown in the peripheral blood (23), and in bronchoalveolar lavage samples (24). O verall, these studies along with the present results point to the potential involvement of $C D 8^{+} T$ lymphocytes in the pathogenesis of COPD. It has been suggested that the recruitment of $\mathrm{CD} 8^{+} \mathrm{T}$ cells may occur in response to repeated episodes of bronchial infection, which are common in the natural history of COPD (13). Whereas this suggestion might explain the increased $C D 8^{+}$phenotype in bronchial biopsy specimens, it seems less likely to explain the characteristics of the inflammatory reaction in pulmonary arteries herein shown. B ecause in patients with $C O P D$ changes in the $C D 4^{+} / C D 8^{+}$ratio are not confined to the bronchial mucosa $(13,22)$, as they have also been reported in peripheral blood $(23,25)$ and in pulmonary arteries (our present results), it might be speculated that tobacco smoking induces an alteration in the lymphocyte regulation that affects extensively the lung structures and contributes to the development of COPD. A Iternatively, as suggested by $O$ 'Shaughnessy and colleagues (13), smokers with a genetically determined low $C D 4^{+} / C D 8^{+}$ratio may be more susceptible to develop COPD.

A potential mechanism for the increased number of inflammatory cells in pulmonary arteries of patients with COPD could be their migration from adjacent bronchioles (26). Indeed, in COPD patients the number of CD $8^{+} T$ lymphocytes infiltrating the airway wall is increased as compared with asymptomatic smokers without airflow obstruction (14). To further investigate this hypothesis, we evaluated separately the leukocyte counts in arteries distant and in those close to the bronchioles. Differences among the three groups were consistent 
in both types of arteries. Interestingly, there was even greater inflammatory cell density in arteries distant to the bronchioles (Figure 2B ), suggesting that the number of cells in pulmonary arteries was not determined by their proximity to peripheral airways. The origin of these inflammatory cells is uncertain. A potential source might be the blood of the pulmonary circulation. H owever, in our series, the majority of cells were located in the adventitia, and not in the intimal or muscular layers, likely suggesting an extraluminal origin. Indeed, in pulmonary muscular arteries, such as those we have examined, the presence of both internal and external elastic laminas may represent an anatomic barrier that impedes the migration of inflammatory cells from the arterial lumen (27). B ecause bronchial arteries also supply the adventitia of pulmonary muscular arteries $(17,28)$, we speculate that inflammatory cells infiltrating the wall of pulmonary muscular arteries in patients with COPD could have originated in the bronchial circulation, in a way similar to that in other lung structures supplied by the bronchial circulation, such as the central and peripheral airways $(12,18)$. H owever, further studies are needed to support this hypothesis.

In our study the number of leukocytes infiltrating the adventitia was correlated with both the endothelium-dependent artery relaxation and the thickening of the intimal layer (Figure 3). This finding is consistent with the hypothesis of a chronic inflammatory process as a potential mechanism for the development of the structural and functional abnormalities of pulmonary circulation in nonhypoxemic patients with mild COPD. Indeed, a significant relationship between the severity of bronchiolar inflammation and the thickness of the intimal layer has been previously reported in several studies (3, $5,6)$. The role of an inflammatory mechanism has been well established in several models of pulmonary hypertension produced by toxic agents (e.g., monocrotaline), sepsis, and hyperoxia (29). Further, inflammatory cells ( $T$ and B lymphocytes) have been described surrounding the plexiform lesions in primary pulmonary hypertension and in other forms of pulmonary hypertension (30). The precise mechanism by which inflammatory cells may induce vascular remodeling and endothelial dysfunction remains unknown. Inflammatory cells may constitute a source of cytokines and growth factors, such as vascular endothelial growth factor (VEGF) and transforming growth factor beta (TGF- $\beta$ ), that may target the endothelial cells and contribute to the development of structural and functional abnormalities of the vessel wall (7). T Iymphocytes and other inflammatory cells may further contribute to the vessel remodeling by directly interacting with endothelial cells and augmenting their permeability to macromolecules, hence contributing to their accumulation at sites of chronic inflammation (31). Furthermore, some proinflammatory cytokines, such as interleukin-1 (IL-1), have also the capability to stimulate fibroblast growth and collagen synthesis, thus amplifying the vessel remodeling process $(32,33)$. T aken together, these data suggest that inflammatory cells may participate in the pathogenesis of the structural abnormalities of pulmonary vessels in patients with mild COPD, likely through the release of both cytokines and growth factors. U nder these conditions, it is not surprising that the degree of endothelium-dependent relaxation of pulmonary arteries was also inversely correlated with the severity of leukocytic infiltrate. B ecause endothelial cells play a key role in the regulation of vascular remodeling, their alteration by cytokines and growth factors released by inflammatory cells may not only promote the vessel remodeling, but also impair the endothelial function. A Iternatively, endothelial dysfunction of pulmonary arteries could result from a direct effect of tobacco smoking on endothelial cells. Indeed, it has been shown that tobacco smoking impairs the endothelium-dependent vasodilation of systemic arteries in a dosedependent manner (34). However, in our study the maximal relaxation to endothelium-dependent vasodilators in smokers did not differ from nonsmokers (Table 2), and the endothelial function was inversely correlated with leukocyte counts (Figure 3). Therefore, we consider that endothelial dysfunction of pulmonary arteries in the early stage of COPD is more likely related to an inflammatory mechanism, rather than to a direct toxic effect of tobacco smoking. In patients with advanced COPD, the coexistence of chronic hypoxemia may further amplify the effects of this inflammatory process, because hypoxic stimulus has been shown to promote the synthesis of growth factors (35) and to adversely affect the endothelial function (1).

In summary, the present study shows an increased inflammatory infiltrate constituted by $C D 8^{+} \mathrm{T}$ lymphocytes in the adventitia of pulmonary muscular arteries in patients with mild COPD, and demonstrates that the intensity of the inflammatory infiltrate is related to both the thickness of the intimal layer and the impairment of the endothelium-dependent artery relaxation. B ecause $\mathrm{CD} 8^{+} \mathrm{T}$-cell infiltrate was also present in pulmonary arteries of smokers without airflow obstruction, the results of this study are consistent with the hypothesis that an inflammatory mechanism, likely related to tobacco smoking, may contribute to the development of the structural and functional alterations of pulmonary circulation in the early stage of COPD.

Acknowledgment: The authors thank the technical staff of the Department of Pathology for their skillful collaboration and L. de Jover for statistical advice.

\section{References}

1. Dinh-X uan, A. T., T. W. Higenbottam, C. Clelland, J. Pepke-Zaba, G . Cremona, A. Y . B utt, S. R. Large, F. C. W ells, and J. W allwork. 1991. Impairment of endothelium-dependent pulmonary-artery relaxation in chronic obstructive lung disease. N. E ngl. J . M ed. 324:1539-1547.

2. Peinado, V . I., J . A . B arberà, J . R amírez, F. P. G ómez, J. R oca, L. J over, J. M. G imferrer, and R. R odriguez-R oisin. 1998. E ndothelial dysfunction in pulmonary arteries of patients with mild COPD. A m. J. Physiol. (L ung Cell. M ol. Physiol.) 274:L 908-L 913.

3. Wright, J. L., L. Lawson, P. D. Paré, R. O. Hooper, D. I. Peretz, J. M. Nelems, M. Schulzer, and J.C. Hogg. 1983. The structure and function of the pulmonary vasculature in mild chronic obstructive pulmonary disease. A m. Rev. Respir. D is. 128:702-707.

4. Magee, F., J. L. W right, B. R. Wiggs, P. D. Paré, and J . C. H ogg. 1988. Pulmonary vascular structure and function in chronic obstructive pulmonary disease. Thorax 43:183-189.

5. B arberà, J . A ., A . R iverola, J. R oca, J. R amírez, P. D . W agner, D . R os, B. R. Wiggs, and R. R odriguez-R oisin. 1994. Pulmonary vascular abnormalities and ventilation-perfusion relationships in mild chronic obstructive pulmonary disease. A m. J. Respir. Crit. Care M ed. 149:423-429.

6. Hale, K. A., S. L. E wing, B. A. Gosnell, and D. E. Niewoehner. 1984. Lung disease in long-term cigarettes smokers with and without chronic air-flow obstruction. A m. Rev. Respir. D is. 130:716-721.

7. Voelkel, N. F., and R. M. Tuder. 1995. Cellular and molecular mechanisms in the pathogenesis of severe pulmonary hypertension. Eur. Respir. J . 8:2129-2138.

8. Riley, D.J ., S. Thakker-V aria, G. J. Poiani, and C. A. Tozzi. 1997. V ascular remodeling. In R. G . Crystal, J . B. W est, P. J . Barnes, and E . R. W eibel, editors. The $L$ ung: Scientific Foundations, 2 nd ed. L ippincottR aven, Philadelphia. 1589-1597.

9. Fournier, M., F. Lebargy, F. Le R oy Ladurie, E. Lenormand, and R. Pariente. 1989. Intraepithelial T-lymphocyte subsets in the airways of normal subjects and of patients with chronic bronchitis. Am. Rev. Respir. D is. 140:737-742.

10. Bosken, C. H., J. H ards, K. G atter, and J . C. Hogg. 1992. Characterization of the inflammatory reaction in the peripheral airways of cigarette smokers using immunocytochemistry. A m. R ev. R espir. D is. 145: 911-917. 
11. Saetta, M ., A. D i Stefano, P. M aestrelli, A . Ferraresso, R. D rigo, A . Potena, A. Ciaccia, and L. M. Fabbri. 1993. A ctivated T-lymphocytes and macrophages in bronchial mucosa of subjects with chronic bronchitis. A m. Rev. Respir. D is. 147:301-306.

12. Di Stefano, A., P. M aestrelli, A. Roggeri, G. Turato, S. Calabro, A. Potena, C. E . M app, A . Ciaccia, L. Covacev, L. M . Fabbri, and M. Saetta. 1994. U pregulation of adhesion molecules in the bronchial mucosa of subjects with chronic obstructive bronchitis. A m. J . Respir. Crit. Care M ed. 149:803-810.

13. O'Shaughnessy, T. C., T. W. A nsari, N. C. Barnes, and P. K. J effery. 1997. Inflammation in bronchial biopsies of subjects with chronic bronchitis: inverse relationship of $C D 8^{+} \mathrm{T}$ Iymphocytes with $\mathrm{FEV} \mathrm{V}_{1}$ A m. J . Respir. Crit. Care M ed. 155:852-857.

14. Saetta, M., A. D i Stefano, G. Turato, F. M. Facchini, L. Corbino, C. E. M app, P. M aestrelli, A . Ciaccia, and L. M. Fabbri. 1998. CD $8^{+}$T Iymphocytes in peripheral airways of smokers with chronic obstructive pulmonary disease. A m. J. Respir. Crit. Care M ed. 157:822-826.

15. Finkelstein, R., R. S. Fraser, H. G hezzo, and M. G. Cosio. 1995. A Iveolar inflammation and its relation to emphysema in smokers. Am. J. Respir. Crit. Care M ed. 152:1666-1672.

16. Peinado, V. I., J . A . B arberà, J. R amírez, F. P. G ómez, J. R oca, and R. $\mathrm{R}$ odriguez-R oisin. 1998. Characterization of the inflammatory reaction in pulmonary arteries of smokers and COPD patients (abstract). A m. J . Respir. Crit. Care M ed. 157:A 381.

17. Wagenvoort, C. A ., and N. W agenvoort. 1977. Pathology of Pulmonary $\mathrm{H}$ ypertension. J ohn Wiley \& Sons, New Y ork.

18. Hogg, J. C. 1993. B ronchiolitis in asthma and chronic obstructive pulmonary disease. Clin. Chest M ed. 14:733-740.

19. Cosio, M., H. G hezzo, J. C. H ogg, R. Corbin, M. Loveland, J. D osman, and P. T. M acklem. 1978. The relations between structural changes in small airways and pulmonary-function tests. N. Engl. J. Med. 298: 1277-1281.

20. G onzalez, S., J. H ards, S. van E eden, and J . C. H ogg. 1996. The expression of adhesion molecules in cigarette smoke-induced airways obstruction. Eur. Respir. J . 9:1995-2001.

21. Nocker, R. E., D. F. Schoonbrood, E. A . van de G raaf, C. E. H ack, R. L utter, H. M. J ansen, and T. A . O ut. 1996. Interleukin-8 in airway inflammation in patients with asthma and chronic obstructive pulmonary disease. I nt. A rch. A llergy I mmunol. 109:183-191.

22. Saetta, M., G. Turato, F. M. Facchini, L. Corbino, R. E. L ucchini, G. Casoni, P. M aestrelli, C. E . M app, A . Ciaccia, and L. M . Fabbri. 1997. Inflammatory cells in the bronchial glands of smokers with chronic bronchitis. A m. J. Respir. Crit. Care M ed. 156:1633-1639.

23. M iller, L. G., G. Goldstein, M. M urphy, and L. C. G inns. 1982. R evers- ible alterations in immunoregulatory T cells in smoking: analysis by monoclonal antibodies and flow cytometry. Chest 82:526-529.

24. Costabel, U ., K. J . B ross, C. R euter, K. H. R uhle, and H. M atthys. 1986. A Iterations in immunoregulatory $\mathrm{T}$-cell subsets in cigarette smokers: a phenotypic analysis of bronchoalveolar and blood lymphocytes. Chest 89:39-44.

25. Y eung, M. C., and D. B uncio. 1984. L eukocyte count, smoking and lung function. A m. J. Med. 76:31-37.

26. A ndoh, Y., S. Shimura, T. A ikawa, H. Sasaki, and T. Takishima. 1992. Perivascular fibrosis of muscular pulmonary arteries in chronic obstructive pulmonary disease. Chest 102:1645-1650.

27. Rome, J. J ., V. Shayani, M. Y. Flugelman, K. D. N ewman, A. Farb, R. V irmani, and D. A . D ichek. 1994. A natomic barriers influence the distribution of in vivo gene transfer into the arterial wall. A rterioscler. Thromb. 14:148-161.

28. D effebach, M. E ., N. B. Charan, S. L akshminarayan, and J . B utler. 1987. The bronchial circulation. A m. Rev. Respir. D is. 135:463-481.

29. Meyrick, B., E. A . Perkett, and K. L. B righam. 1987. Inflammation and models of chronic pulmonary hypertension. A m. Rev. Respir. D is. 136: 765- 767.

30. Tuder, R. M., B. Groves, D. B. Badesch, and N. F. V oelkel. 1994. Exuberant endothelial cell growth and elements of inflammation are present in plexiform lesions of pulmonary hypertension. A m. J. Pathol. 144: 275-285.

31. D amle, N. K ., and L. V . D oyle. 1990. A bility of human T Iymphocytes to adhere to vascular endothelial cells and to augment endothelial permeability to macromolecules is linked to their state of post-thymic maturation. J . I mmunol. 144:1233-1240.

32. H umbert, M., G. M onti, F. B renot, O. Sitbou, A. Portier, L. G ranjeotKeros, P. D uroux, P. G alanaud, G. Simonneau, and D. E milie. 1995. Increased interleukin-1 and interleukin- 6 serum concentration in severe primary pulmonary hypertension. A m. J. Respir. C rit. Care M ed. 151:1628-1631.

33. Voelkel, N. F., and R. M. Tuder. 1994. Interleukin-1 receptor antagonist inhibits pulmonary hypertension induced by inflammation. N.Y. A cad. Sci. 3:1711.

34. Celermayer, D. S., K. E. Sorensen, V. M. G ooch, D. J. Spiegelhalter, O. M iller, I. D. Sullivan, J . K . L loyd, and J. E . D eanfield. 1992. N on-invasive detection of endothelial dysfunction in children and adults at risk of atherosclerosis. L ancet 340:1111-1115.

35. Knighton, D. R., T. K. H unt, H. Scheuenstuhl, and B.J . H alliday. 1983. Oxygen tension regulates the expression of angiogenesis factor by macrophages. Science 221:1283-1285. 